\title{
Hydrogen, microstructure and defect density in hydrogenated amorphous silicon
}

\author{
P. Roca i Cabarrocas $\left({ }^{1}\right)$, Z. Djebbour $\left({ }^{2}\right)$, J. P. Kleider $\left({ }^{2}\right)$, C. Longeaud $\left({ }^{2}\right)$, D. \\ Mencaraglia $\left({ }^{2}\right)$, J. Sib $\left({ }^{2}\right)$, Y. Bouizem $\left({ }^{3}\right)$, M. L. Thèye $\left({ }^{3}\right)$, G. Sardin $\left({ }^{4}\right)$ and J. P. \\ Stoquert $\left(^{5}\right)$
}

(') Laboratoire de Physique des Interfaces et des Couches Minces (UPR 258-CNRS), Ecole Polytechnique, F-91128 Palaiseau Cedex, France

(2) Laboratoire de Génie Electrique de Paris (URA 0127-CNRS), Universités Paris VI et Paris XI, Ecole Supérieure d'Electricité, Plateau de Moulon, F-91192 Gif-sur-Yvette Cedex, France

( $\left.{ }^{3}\right)$ Laboratoire d'Optique des Solides (URA 0781 CNRS), Université Pierre-et-Marie-Curie, 4, place Jussieu, F-75252 Paris Cedex 05, France

(4) Departament de Fisica Aplicada i Electrònica, Universitat de Barcelona, Av. Diagonal 645, E08028 Barcelona, Spain

(5) Centre de Recherches Nucléaires, BP 20,67037 Strasbourg Cedex, France

(Received 21 February 1992, accepted Il June 1992)

Résumé. - Il est admis qu'en s'attachant aux liaisons pendantes du silicium, l'hydrogène réduit la densité d'états du silicium amorphe et fait de ce matériau un semi-conducteur apte aux applications électroniques. Pour des échantillons «standard », élaborés à partir de la décomposition du silane dans un plasma de décharge $R F$ à faible vitesse de dépôt $(\approx 1 \AA / \mathrm{A})$, nous observons que la présence d'une bande d'absorption à $2090 \mathrm{~cm}^{-1}$ dans le spectre infrarouge est corrélée avec une densité de défauts élevée dans le matériau. Cependant, cette corrélation n'est valable que dans une plage réduite dans l'espace des paramètres de dépôt. De plus, nous avons observé que le a-Si : H élaboré à partir de mélanges silane-hélium à des vitesses élevées $(8-16 \AA / s)$ présente une forte bande d'absorption à $2090 \mathrm{~cm}^{-1}$, bien que la densité de défauts soit faible. Nous présentons ici les résultats d'une étude sur les propriétés opto-électroniques de couches minces de a-Si : $\mathrm{H}$ préparées sous différentes conditions de plasma. Nos résultats montrent que l'on peut élaborer des matériaux a-Si : H très différents avec une faible densité d'états. Il est donc envisageable de choisir les conditions d'élaboration de façon à obtenir les propriétés opto-électroniques souhaitées pour différentes applications.

Abstract. - It is well established that by bonding with the dangling bonds of silicon, hydrogen reduces the density of states of amorphous silicon and renders this material suitable to electronic applications. For so-called «standard»a-Si:H films deposited by the RF glow discharge decomposition of silane at low deposition rates $(\approx 1 \AA / s)$ and over a large range of deposition temperatures, we observed the usual correlation between the hydrogen bonding and the defect density in the as-deposited material only. It clearly appears that the widely accepted correlation between the hydrogen bonding, the microstructure and the defect density only applies to a limited set of deposition parameters. Moreover we found that the deposition of a-Si : $\mathrm{H}$ from mixtures of 
silane in helium at high deposition rates $(8-16 \AA / s)$ results in a material with a very different hydrogen-related structure and with a low defect density. We here present the results of a study of the optoelectronic properties of a-Si : $\mathrm{H}$ films deposited by an $\mathrm{RF}$ glow discharge under different plasma conditions. Our results show that, aecording to the deposition conditions, different a-Si : $\mathrm{H}$ materials can be prepared. It is thus possible to tailor the deposition conditions in order to get the desired optoelectronic properties for a given application of the material.

\section{Introduction.}

With respect to the ideal situation represented by crystalline silicon, amorphous silicon (a-Si) does not exhibit long range order. However, the bond lengths and bond angles of a silicon atom with its four neighbours are only slightly modified with respect to the crystalline situation so that local order still exists. The structural disorder and the presence of a large proportion of unsatisfied bonds result respectively in the formation of tails of localized states at each band edge and of a distribution of localized defect states deeper in the gap.

In 1879 Ogier [1] reported on the decomposition of the gas silane $\left(\mathrm{SiH}_{4}\right)$ in an electric discharge and the production of amorphous silicon. Almost one hundred years later, Chittick et al. [2] reported again on the elaboration of amorphous silicon films by the decomposition of silane in an RF glow discharge and on the photoconductive properties of this material ; very slight doping effects were observed when phosphine $\left(\mathrm{PH}_{3}\right)$ was added to silane. But it was the demonstration by Spear and Le Comber [3] of the possibility of doping such films, deposited under appropriate conditions, which promoted the interest in this new disordered semiconductor, where however the beneficial presence of bonded hydrogen was long to be acknowledged. During the last two decades, the effort of all the research groups worldwide has been focussed on the optimization of the deposition conditions (RF powe $\bar{r}$, gas pressure, gas flow rate and composition, geometry of the reactor, and substrate temperature) in order to produce hydrogenated amorphous silicon (a-Si : H) with a low density of states in the pseudogap suitable for applications in thin film electronic devices.

The optimization of an a-Si : $\mathrm{H}$ means :

i) a reduction of the number of unsatisfied (dangling) silicon bonds which give rise to defect states in the bandgap of the semiconductor. In this respect, the incorporation of hydrogen is of crucial importance, since it has been shown that hydrogen passivates the defects (dangling bonds) by bonding to silicon dangling bonds [4]. This results in a decrease of the defect state density by about four orders of magnitude in optimized material ;

ii) a reduction of the structural disorder, i.e. a reduction of the extent of the band tails into the gap.

The worldwide effort on the optimization of the deposition conditions has led to an a-Si : $\mathrm{H}$ with a low density of states $\left(<16^{16} \mathrm{~cm}^{-3} \mathrm{eV}^{-1}\right)$, which is successfully used in many thin film devices [5]. All the research groups converged towards the same well defined optimal deposition conditions : low RF power $\left(10-100 \mathrm{~mW} / \mathrm{cm}^{2}\right)$ and low gas pressure (3-10 Pa), the substrate temperature $T_{\mathrm{s}}$ ranging from 150 to $300{ }^{\circ} \mathrm{C}[6]$. From a structural point of view, the films deposited under such conditions are dense and present little, if any, micro-heterogeneity ; hydrogen is essentially incorporated as isolated monohydride $\mathrm{Si}-\mathrm{H}$ groups and there is no hydrogen evolution at low temperatures $\left(<400^{\circ} \mathrm{C}\right)$. On the contrary, the films deposited under non-optimized deposition conditions, and which exhibit a high defect density, usually contain a significant proportion of dihydride or polyhydride $\mathrm{Si}-\mathrm{H}_{2}$ or $\left(\mathrm{Si}-\mathrm{H}_{2}\right)_{n}$ groups and show low temperature hydrogen evolution. Therefore, for the a-Si : H films deposited under the above «standard» plasma conditions, some correlation between the microstructure and the 
electronic properties of a-Si : $\mathrm{H}$ can be found $[7,8]$. However, the «standard " deposition conditions yield low deposition rates $(\sim 1 \AA / s)$ and highly stressed films, two major drawbacks for the deposition of thick layers because of the long deposition times and the problems of peeling off associated with the internal stress in the film.

In order to increase the deposition rate of a-Si : $\mathrm{H}$, we developed a new process in which a-Si : $\mathrm{H}$ is deposited from a mixture of silane and helium at high pressure (74 $\mathrm{Pa}$ ) and higher $\mathrm{RF}$ power. Under these conditions, the discharge switches to the so-called $\gamma$ regime [9]. We have thus been able to increase the deposition rate by more than a factor of ten while keeping the low defect density of the optimized « standard " a-Si : $H[10,11]$. However, a detailed characterization of these films reveals significant differences, with respect to the "standard » samples, concerning the correlation between their hydrogen-related microstructure and their defect density as well as the presence of metastable effects due to thermal quenching [12].

We here present a comparative study of the hydrogen-related properties and the defect density of «standard $» \mathrm{a}-\mathrm{Si}: \mathrm{H}$ films deposited at two different temperatures $\left(100{ }^{\circ} \mathrm{C}\right.$ and $250^{\circ} \mathrm{C}$, respectively non-optimized type 1 and optimized type 2 materials) and of a-Si: $\mathrm{H}$ films deposited by our new process from a mixture of $40 \%$ silane in helium at $250{ }^{\circ} \mathrm{C}$ (optimized material type 3 ).

\section{Experimental.}

The films used in this study were deposited in a hot-wall multiplasma-monochamber reactor [6] by the RF (13.56 MHz) glow discharge decomposition of pure silane (« standard» material) or of a mixture of $40 \%$ silane in helium ( $«$ helium-diluted » films). The deposition conditions of the three film series are given in table $I$. We emphasize that these films are representative of the given deposition conditions and are not particular ones.

Table I. - Deposition conditions of the three types of samples used in this study.

\begin{tabular}{|c|c|c|c|c|c|}
\hline $\begin{array}{c}\text { Type of } \\
\text { sample }\end{array}$ & $\begin{array}{c}\mathrm{SiH}_{4} \\
(\%)\end{array}$ & $\begin{array}{c}\text { Pressure } \\
(\mathrm{Pa})\end{array}$ & $\begin{array}{c}\text { Temperature } \\
\left({ }^{\circ} \mathrm{C}\right)\end{array}$ & $\begin{array}{c}\text { RF power } \\
\left(\mathrm{mW} / \mathrm{cm}^{2}\right)\end{array}$ & $\begin{array}{c}\text { Deposition rate } \\
(\AA / \mathrm{s})\end{array}$ \\
\hline « standard »(1) & 100 & 6 & 100 & 5 & 0.5 \\
\hline « standard » (2) & 100 & 6 & 250 & 5 & 0.7 \\
\hline He-diluted (3) & 40 & 74 & 250 & 85 & 8 \\
\hline
\end{tabular}

The hydrogen bonding configurations were obtained from infrared transmission measurements performed on samples deposited on crystalline silicon substrates. The bonded hydrogen content was deduced from the integrated intensity of the wagging band centred around $640 \mathrm{~cm}^{-1}$, which has been shown to be proportional to the hydrogen content with the same proportionality constant whatever the hydrogen content and the film microstructure [13]. The atomic density of hydrogen was obtained from :

$$
N_{\mathrm{H}}=A \int \frac{\alpha(\omega)}{\omega} \mathrm{d} \omega
$$

with $A=1.6 \times 10^{19} \mathrm{~cm}^{-2}[13,14]$. The hydrogen atomic concentration was calculated from the ratio between $N_{\mathrm{H}}$ and the atomic density of silicon $N_{\mathrm{Si}}=5 \times 10^{22} \mathrm{~cm}^{-3}$ The microstruc- 
ture parameter $R$, considered for «standard $» \mathrm{a}-\mathrm{Si}: \mathrm{H}$ as the signature of a poor quality material [15], was determined from the ratio of the integrated intensity of the stretching band centered at about $2090 \mathrm{~cm}^{-1}$, usually ascribed to $\mathrm{SiH}_{2}$ and $\left(\mathrm{SiH}_{2}\right)_{n}$ groups which also produce an IR absorption in the $800-900 \mathrm{~cm}^{-1}$ range, to that of the whole stretching band, i.e. the band at $2090 \mathrm{~cm}^{-1}$ plus the band at $2000 \mathrm{~cm}^{-1}$ attributed to isolated $\mathrm{SiH}$ groups :

$$
R=\frac{[2090]}{[2090]+[2000]}
$$

The type of hydrogen bonding, i.e. tightly bonded hydrogen $\mathrm{TBH}$, leaving the film at high temperatures only, as opposed to weakly bonded hydrogen WBH responsible for a low temperature evolution peak, was also studied by hydrogen evolution experiments performed on the same samples deposited on crystalline silicon substrates [16-18]. Moreover, elastic recoil detection analysis (ERDA) measurements were performed to obtain the total hydrogen content of the films [19].

The thickness $d$, the energy dispersion of the refractive index $n_{(h \nu)}$, and the optical gap $E_{04}$ (defined as the energy at which the absorption coefficient $\alpha$ is equal to $10^{4} \mathrm{~cm}^{-1}$ ) of the films deposited on 7059 Corning glass substrates were deduced from the analysis of transmission measurements performed in the visible and near infrared range. The $n(h \nu)$ variation was analyzed according to the Wempel-Didomenico one oscillator model [20] in order to derive the average gap $E_{\mathrm{g}}$ and the static refractive index $n_{(0)}$. The optical absorption coefficient for energies smaller than the optical gap was determined by photothermal deflection spectroscopy measurements (PDS) performed on the same samples used for the transmission measurements. The PDS spectra were carefully calibrated by fitting to the film absorbance computed from the optical data in the $\alpha \sim 10^{3}-10^{4} \mathrm{~cm}^{-1}$ range. The absorption coefficient spectra thus obtained down to $0.6 \mathrm{eV}$ provide information about the density of localized states in the lower part of the gap. Indeed, for photon energies smaller than the optical gap $E_{04}$ the absorption coefficient first follows an exponential decay with photon energy $h \nu$ :

$$
\alpha=\alpha_{0} \exp \left(h \nu / E_{0}\right)
$$

The inverse slope $E_{0}$ of this exponential part of the absorption edge represents the width of the valence band tail, related to the structural disorder of the film; it is commonly designated as the Urbach energy. At lower energies, the absorption coefficient flattens out due to the absorption by deep defect states, usually associated to dangling bonds. This defect absorption is thought to be dominated by the contribution of filled neutral dangling bond states. According to Amer and Jackson, the deep defect density can be estimated from the integration of the excess subgap absorption $\Delta \alpha_{\text {PDS }}=\alpha-\alpha_{0} \exp \left(h \nu / E_{0}\right)$ [21]. By comparing their results to those of spin density measurements, they deduced the relation :

$$
N_{\mathrm{D}}\left(\mathrm{cm}^{3}\right)=7.9 \times 10^{15} \int \Delta \alpha_{\mathrm{PDS}} \mathrm{d}(h \nu) .
$$

Such an estimate of the defect density can be used (like any other calibration procedure) in comparative studies of films with similar optical gaps and Urbach energies.

The defect state distribution and density in the upper half of the gap were deduced from modulated photocurrent measurements [22] performed on samples deposited on 7059 Corning glass substrates provided, prior to a-Si : $\mathrm{H}$ deposition, with thermally evaporated coplanar chromium contacts. These samples were also used for dark conductivity measurements.

Schottky diodes were obtained by electron beam evaporation of platinum onto films deposited on chromium-covered glass substrates. They were used in i) capacitance versus bias, 
temperature, and frequency measurements $C(V, T, w)$, from which the density of states at the Fermi level $g\left(E_{\mathrm{F}}\right)$ and its integral between the Fermi level $E_{\mathrm{F}}$ and midgap were deduced [23]; ii) time-of-flight (TOF) [24] and post-transit experiments [25] from which the electron drift mobility $\mu_{\mathrm{e}}$ and the defect state distribution and density from the conduction band mobility edge down to $E_{\mathrm{F}}$ were deduced ; and iii) surface photovoltage measurements (SPV) from which the diffusion length of the minority carriers (holes) $L_{\mathrm{p}}$ was obtained [26]. Two techniques are mainly used to gain information on the minority carrier limited transport in undoped a-Si : H : the Steady State Photocarrier Grating (SSPG) and the Surface Photovoltage (SPV) techniques. Both have their advantages and limitations $[27,28]$. From our experience, we can say that if SPV measurements are performed on a junction device thick enough to have a clear cut separation of the front and back space charge regions [29], and if the superimposed dc bias light, necessary to collapse the space charge width in order to promote a diffusion-dominated carrier flow, is of sufficient intensity [26], then the information derived from this technique is reliable and generally in good agreement with the SSPG ones [29]. An example of a check of the second condition is given in figure 1, in which the SPV-derived characteristic length is plotted versus the superimposed dc bias light intensity. It is clear that a constant value of this characteristic length is reached for a light intensity greater than $1 \mathrm{~mW} . \mathrm{cm}^{-2}$. This asymptotic value, which generally compares well with the ambipolar SSPG-derived diffusion length, is here considered to be representative of the hole-limited carrier flow and will be called $L_{\mathrm{p}}$. In the following, the values of $L_{\mathrm{p}}$ given for each type of sample have been obtained according to this procedure.

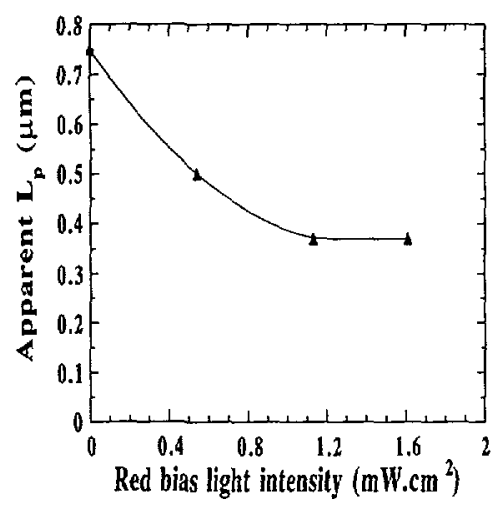

Fig. 1. - The SPV-derived apparent diffusion length versus the superimposed dc bias light intensity for a sample of type 3 ; the asymptotic value at high bias light level is equal to $L_{\mathrm{p}}=0.37 \mu \mathrm{m}$.

It is worthwhile noticing that from a TOF experiment performed at a temperature $T$ with an applied field $\zeta$ the conduction band-tail density of states was derived from the expression :

$$
N(E)=(\zeta / d)\left\{N\left(E_{\mathrm{c}}\right) \mu_{0} / \nu_{0}\right\}(1-\alpha)
$$

where $\alpha=T / T_{\mathrm{c}}$ is a dispersion parameter, $\mathrm{d}$ the sample thickness, $\nu_{0}$ the attempt-to-escape frequency, $N\left(E_{\mathrm{c}}\right)$ the density of states at the conduction band mobility edge, and $\mu_{0}$ the electron mobility in the conduction extended states (free carrier mobility). As discussed below, we obtained $N(E)$ by assuming that $\mu_{0}$ and $\nu_{0}$ are the same for all the samples. 


\section{Results.}

3.1 HYDROGEN-RELATED PROPERTIES. - As explained before, the analysis of the infra-red absorption spectra allows not only to determine the bonded hydrogen content from the integrated intensity of the wagging band centered at about $640 \mathrm{~cm}^{-1}$ but also to obtain information on the hydrogen bonding configurations from the line shape and the respective intensities of the stretching and bending bands located in the $2000-2100$ and $800-900 \mathrm{~cm}^{-1}$ range respectively. The values of the atomic concentration of bonded hydrogen and of the microstructure parameter $R$ for thick $(3-6 \mu \mathrm{m})$ as-deposited samples of types 1 to 3 are given in table II, together with the values of the total concentration of atomic hydrogen as deduced by ERDA.

Table II. - Hydrogen-related properties (optical gap $E_{04}$ and refractive index $n_{(2 \mu \mathrm{m})}$ of the three types of samples used in this study. The total hydrogen and the bonded hydrogen contents were respectively determined by ERDA and IR techniques.

\begin{tabular}{|c|c|c|c|c|c|c|c|}
\hline $\begin{array}{c}\text { Type of } \\
\text { sample }\end{array}$ & $\begin{array}{c}\text { Thickness } \\
(\mu \mathrm{m})\end{array}$ & $\begin{array}{c}\text { Total H } \\
(\%)\end{array}$ & $\begin{array}{c}\text { Bonded H } \\
(\%)\end{array}$ & $R$ & $\begin{array}{c}E_{04} \\
(\mathrm{eV})\end{array}$ & $\begin{array}{c}E_{\mathrm{g}} \\
(\mathrm{eV})\end{array}$ & $n_{(0)}$ \\
\hline $\mathbf{1}$ & 3.2 & 17 & 14 & 0.33 & 1.94 & 3.67 & 3.54 \\
\hline $\mathbf{2}$ & 4.4 & 10 & 7 & 0.06 & 1.89 & 3.41 & 3.75 \\
\hline $\mathbf{3}$ & 6.0 & 16 & 14 & 0.40 & 1.93 & 3.67 & 3.63 \\
\hline
\end{tabular}

It can first be seen that, although there is a systematic difference between the ERDA and the infra-red results, the hydrogen content values show the same trends : they are rather high and about the same for type 1 and $\mathbf{3}$ samples and much lower for type $\mathbf{2}$ samples. The difference between the estimated total and bonded hydrogen content can be attributed to :

i) experimental errors in the analysis of the IR measurements, resulting mainly from the determination of the film thickness and of the base-line of the wagging absorption band. For the thick films considered here we estimate the error on the band integrated intensity of about $5 \%$; this is comparable to the scatter of the results for different films deposited under identical conditions. Due to calibration problems, the error on the ERDA results is of the order of $10 \%$;

ii) errors in the calibration constant $A$, since it is well known that the oscillator strength of the different vibration modes can be modified by their structural environment. However this phenomenon seems to be negligible for the wagging band, and the widely accepted value which we used was shown to be independent both of the hydrogen content and of the preparation conditions of the samples [13]. The fact that the difference between the ERDA and the infra-red results is the same for the three types of samples, which certainly have very different microstructures, tends to confirm this conclusion;

iii) the presence of molecular hydrogen, which is not detected by our IR measurements but contributes to the ERDA results. It has indeed been shown that microvoids in a-Si : $\mathrm{H}$ are filled with molecular hydrogen under high pressure $(\sim 2 \mathrm{kbar})$ and that this molecular hydrogen can amount to $1 \%[30,31]$. At present we have no means to evaluate the contribution of molecular hydrogen to the observed difference between the ERDA and the infra-red results. 
We now turn to the analysis of the stretching and bending absorption bands, which are shown in figure 2 for the as-deposited samples of type 1 to 3 . For the «standard sample deposited at $250^{\circ} \mathrm{C}$ (type 2 ), the stretching band essentially consists in a single band centered at $2000 \mathrm{~cm}^{-1}$, which shows that the hydrogen is mainly incorporated as isolated monohydride $\mathrm{Si}-\mathrm{H}$ groups. The deconvolution of the band into two Gaussians reveals the presence of a very small contribution centered at about $2080 \mathrm{~cm}^{-1}(R=0.06)$. This component can be related to the faint bending band consisting of a single asymmetric peak centered at about $860 \mathrm{~cm}^{-1}$, and is thus ascribed to a small proportion of $\mathrm{SiH}_{2}$ groups. The spectra for the «standard » samples deposited at $100{ }^{\circ} \mathrm{C}$ (type 1) are markedly different, since the stretching band exhibits, besides the $\mathrm{Si}-\mathrm{H}$ component at $2000 \mathrm{~cm}^{-1}$, a relatively large contribution centered at $2070 \mathrm{~cm}^{-1}$ $(R=0.33$ ). This contribution can be correlated to a distinct bending band, which now consists of two well-resolved peaks centered at about 880 and $840 \mathrm{~cm}^{-1}$ respectively. This indicates an important proportion of $\left(\mathrm{SiH}_{2}\right)_{n}$ groups, which for « standard » samples is usually considered to be a sign of a poor quality material $[8,32]$; this is indeed verified here, as discussed in section 3.2. Turning now to the « helium-diluted » samples deposited at $250^{\circ} \mathrm{C}$ (type 3 ), we can see that their infra-red absorption spectra are very similar to those of type 1 samples. The stretching band indeed contains a large contribution centered at $2080 \mathrm{~cm}^{-1}(R=0.40)$, and the bending band also consists of an even better resolved doublet at about 890 and $850 \mathrm{~cm}^{-1}$, the relative intensity of the two peaks being about the same. Besides, the ratio of the integrated intensity of the $2070-2080 \mathrm{~cm}^{-1}$ stretching band to that of the whole bending band is practically the same in both cases $(\sim 7)$. This might indicate that if, besides the $\mathrm{SiH}_{2}$ groups, $\mathrm{SiH}$ groups at internal surfaces or in microvoids contribute to the $2070-2080 \mathrm{~cm}^{-1} \mathrm{band}$, as suggested by many authors, their contribution should be the same for both types of samples ( 1 and 3 ). It can then be concluded that both the total and bonded hydrogen content and the bonding hydrogen configurations are very similar in the as-deposited samples of types 1 and 3 , although, as discussed below, their defect density is very different. Slight differences between the positions and widths of the features associated with $\left(\mathrm{SiH}_{2}\right)_{n}$ groups could however reveal differences in the local environment of the $\mathrm{Si}-\mathrm{H}$ bonds.

In table II we also present the optical parameters $E_{04}, E_{\mathrm{g}}$, and $n_{(0)}$ for the three types of films. For the «standard » samples, the optical gap $E_{04}$ as well as the average gap decreases along with the hydrogen content, as usually observed [33]. For the «helium-diluted samples the same trend seems to apply. The static refractive index $n_{\langle 0\rangle}$, which can be related to the film density, presents an interesting behaviour. Indeed, while for the « standard " films we observe that $n_{(0)}$ decreases as the hydrogen content increases, the type 3 films have a higher refractive index than the type 1 films, even though their hydrogen content is about the same and their microstructure parameter $R$ is higher.

The hydrogen evolution spectra of a « standard » a-Si : $\mathrm{H}$ sample deposited at $250{ }^{\circ} \mathrm{C}$ (type 2) is shown in figure 3 . We observe that hydrogen starts to evolve around $350{ }^{\circ} \mathrm{C}$ and that the evolution is symmetric and limited by the diffusion of the hydrogen through the compact a-Si : $\mathrm{H}$ film. The spikes appearing at low temperatures are associated to molecular hydrogen desorbed from the sample surface; but we do not observe any hydrogen evolution at low temperature. Now, we have always observed a direct correlation between the presence of an absorption band at $2080 \mathrm{~cm}^{-1}$ in the IR spectra and the low temperature evolution of « weakly bonded $\gg$ hydrogen (WBH) [18, 34]. Accordingly, we expected an important WBH evolution for the « helium-diluted » samples (type 3 ). Yet, as seen in figures $4 \mathrm{a}$ and $4 \mathrm{~b}$, not only do the evolution spectra of these samples not exhibit any low temperature peak, but the hydrogen seems to be even more «tightly bonded » than in the "standard " a-Si: $\mathrm{H}$ films deposited between 200 and $300^{\circ} \mathrm{C}$. Indeed, the main part of the hydrogen evolves at a very high temperature $\left(\sim 650^{\circ} \mathrm{C}\right)$ compared to that of the «standard $»$ films $\left(\sim 550^{\circ} \mathrm{C}\right)$. Besides, the 

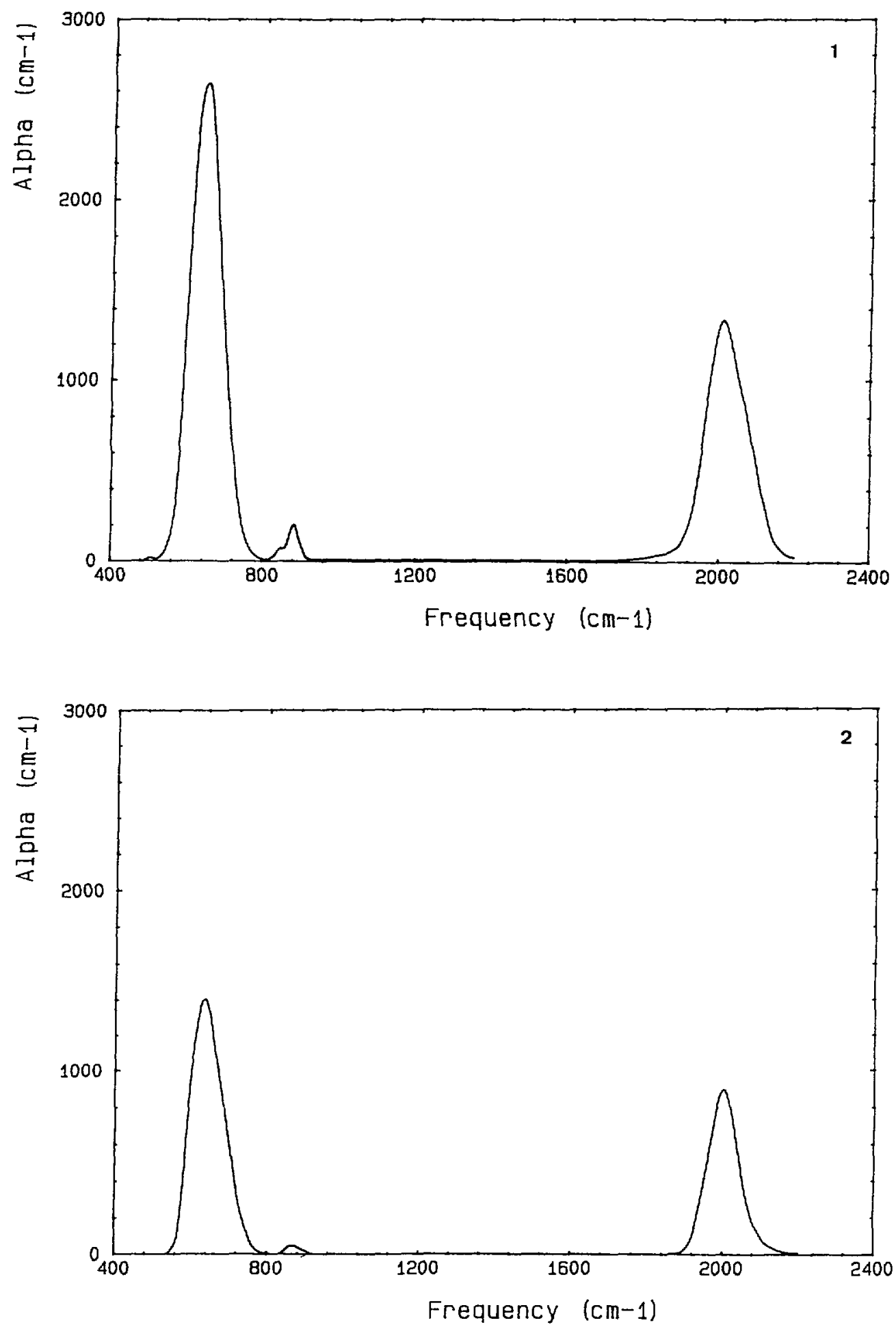

Fig. 2. - The infrared absorption spectra of a $3.25 \mu \mathrm{m}$ thick « standard » a-Si : $\mathrm{H}$ film deposited at $100{ }^{\circ} \mathrm{C}(1)$, a $4.4 \mu \mathrm{m}$ thick «standard $» \mathrm{a}-\mathrm{Si}: \mathrm{H}$ film deposited at $250^{\circ} \mathrm{C}(2)$, and a $6 \mu \mathrm{m}$ thick a-Si : $\mathrm{H}$ film deposited at $250^{\circ} \mathrm{C}$ from a mixture of $40 \%$ silane in helium (3). 


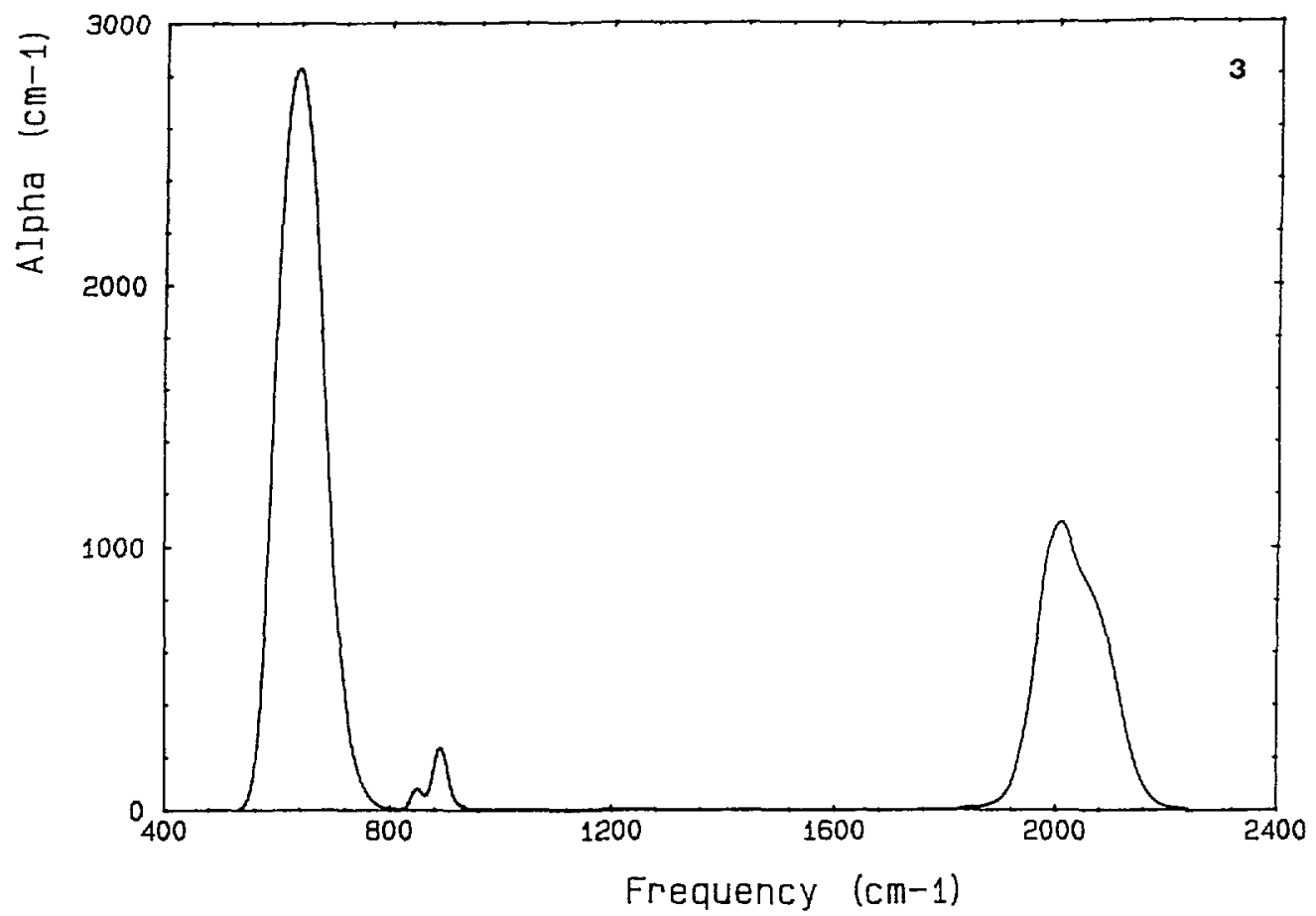

Fig. 2 (suite).

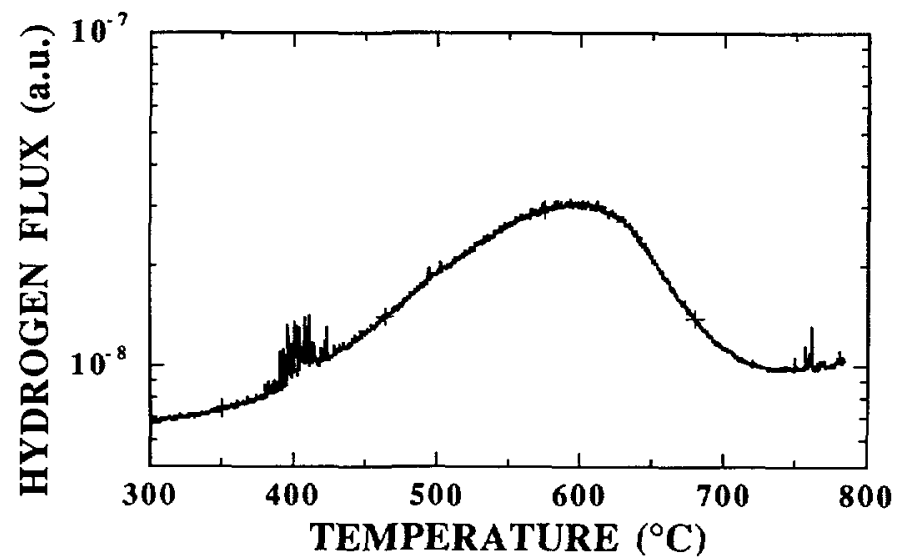

Fig. 3. - The hydrogen evolution spectra of «standard » a-Si : $\mathrm{H}$ film deposited at $250^{\circ} \mathrm{C}$.

evolution peak is quite narrow, while for the « standard » samples it is always much broader. Figure $4 \mathrm{~b}$ also shows for comparison the evolution spectrum of another optimized « heliumdiluted" sample deposited at a higher rate $(\sim 15 \AA / \mathrm{s})$ at the same temperature $T_{\mathrm{s}}=$ $250{ }^{\circ} \mathrm{C}$ but at a higher $\operatorname{RF}$ power $[10,11]$. This spectrum is essentially similar to that of figure $4 \mathrm{a}$, with a sharp peak at an even higher temperature ; the only difference is the slowly increasing evolution above $450^{\circ} \mathrm{C}$. It must be emphasized that the data presented in figures 3 and 4 were obtained with the same experimental set-up, at the same heating rates, and on films 

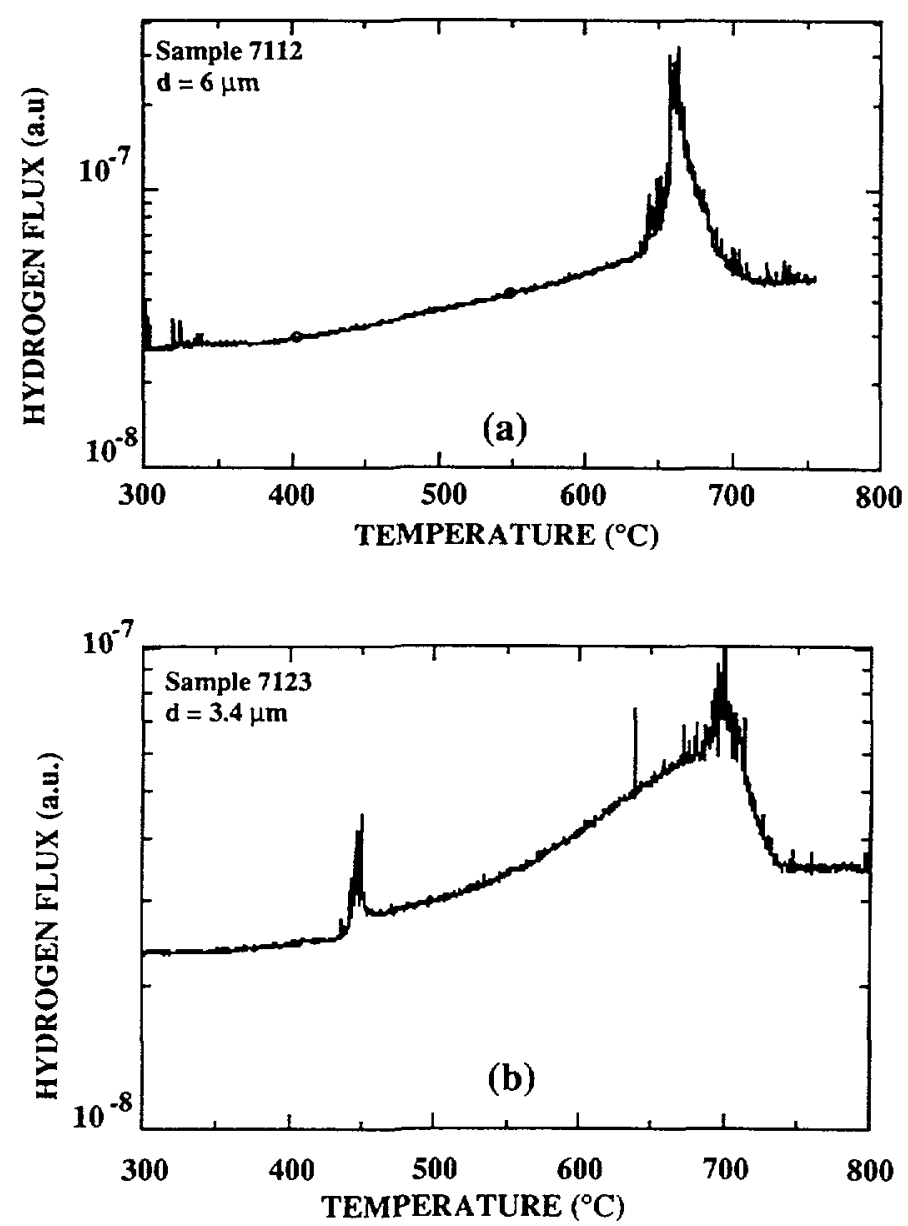

Fig. 4. - The hydrogen evolution spectra of a-Si : $\mathrm{H}$ films deposited at $250{ }^{\circ} \mathrm{C}$ from a mixture of $40 \%$ silane in helium (type 3) at high deposition rates : (a) $8 \AA / \mathrm{s}$ and (b) $15 \AA / \mathrm{s}$.

with similar thicknesses. This kind of hydrogen evolution, characteristic of optimized « helium-diluted » films, has to be related to the particular deposition conditions and suggests a different microstructure of the a-Si : $\mathrm{H}$ network, in agreement with the higher values of the static refractive index.

3.2 DEFECT DENSITY. - As pointed out in the introduction, it is generally accepted that low defect density a-Si : $\mathrm{H}$ films are obtained by RF glow discharge of pure silane at low pressure, low $\mathrm{RF}$ power, and $150 \leqslant T_{\mathrm{s}} \leqslant 300^{\circ} \mathrm{C}$, giving deposition rates of $\sim 1 \AA / \mathrm{s}$ [6]. Moreover, the presence of the infrared absorption band at $2080 \mathrm{~cm}^{-1}$ is considered to be a sign of poor quality a-Si : H. However, we have already shown that, despite their large $R$ values, the subgap optical absorption determined by PDS on the films of type 3 is as low as that of the optimized «standard » a-Si : $\mathrm{H}$, which indicates that this « helium-diluted » a-Si: $\mathrm{H}$ has a low defect density [11]. Here we present the results of a complete characterization of the defect density in the gap and in both bandtails by different complementary techniques.

Figure 5 shows the absorption coefficient determined from optical transmission and PDS measurements for the three types of samples. The «standard "a-Si:H samples exhibit the 


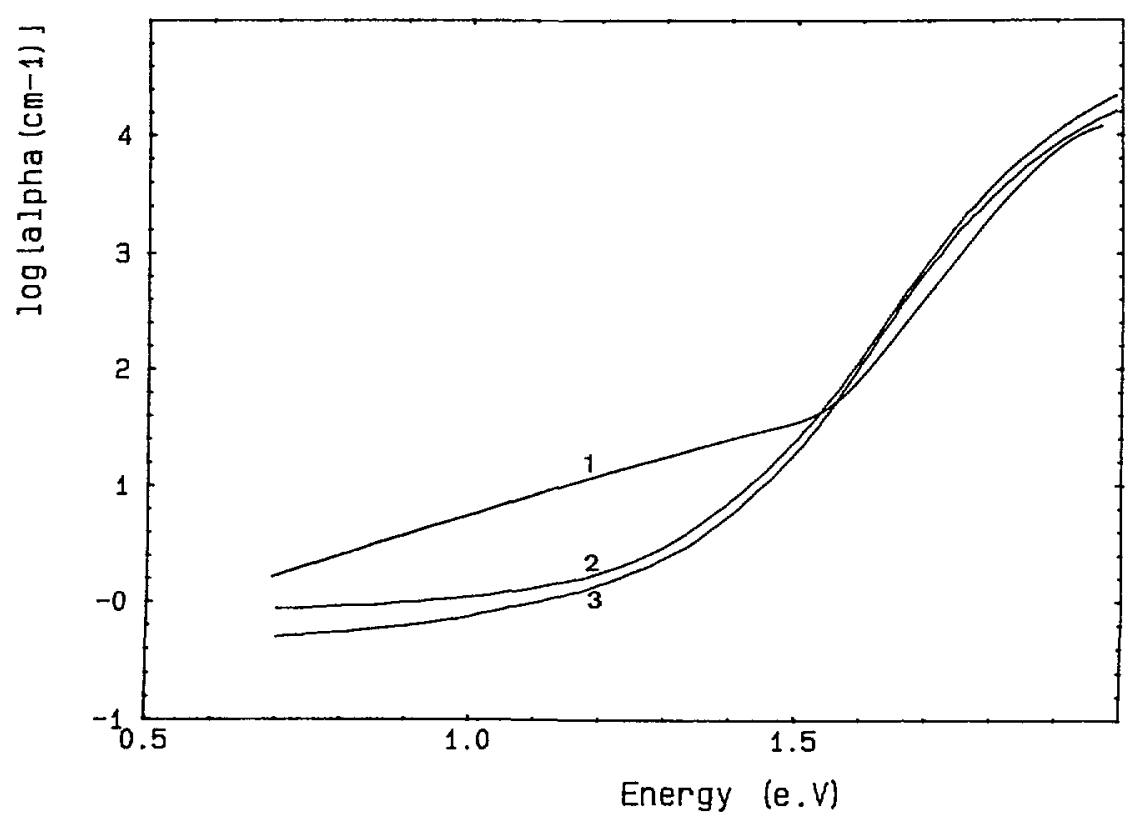

Fig. 5. - The optical absorption spectra determined by PDS measurements for the three types of a-Si : H samples.

general behaviour, i.e. their defect density related to the optical absorption in the low energy range $(<1.5 \mathrm{eV})$, and their disorder, related to the Urbach energy representing the width of the valence band tail (VBT), are higher at low temperature (Tab. III) and can be correlated to the infrared absorption spectra. On the other hand, the « helium-diluted " sample (type 3) has an absorption spectrum in the Urbach edge region as well as in the low energy range almost identical to the typical ones of the "standard "films deposited at the same temperature $\left(250{ }^{\circ} \mathrm{C}\right.$ ) but at much lower deposition rates (type 2). Then, despite their striking differences in the hydrogen content and bonding, the films of types 2 and 3 have similar structural disorder and similar defect density. Clearly, the «microstructure parameter $~ R$ defined from the IR spectra bears no relation to the structural disorder of these films. It is worthwhile noticing that a detailed deconvolution of the subgap absorption spectrum derived from photoconductivity (CPM) measurements leads to some differences in the position of the defect band assumed to be gaussian, namely the peak of the gaussian distribution is closer to the valence band by about

Table III. - Electronic properties of the three types of samples used in this study.

\begin{tabular}{|c|c|c|c|c|c|c|}
\hline $\begin{array}{c}\text { Type of } \\
\text { sample }\end{array}$ & $\begin{array}{c}N_{\mathrm{D}} \\
\left(\mathrm{cm}^{-3}\right)\end{array}$ & $\begin{array}{c}E_{0} \\
(\mathrm{meV})\end{array}$ & $\begin{array}{c}g\left(E_{\mathrm{F}}\right) \\
\left(\mathrm{cm}^{-3} \mathrm{eV}^{-1}\right)\end{array}$ & $\begin{array}{c}I_{\mathrm{mg}} \\
\left(\mathrm{cm}^{-3}\right)\end{array}$ & $\begin{array}{c}\mu_{\mathrm{e}} \\
\left(\mathrm{cm}^{2} \mathrm{~V}^{-1} \mathrm{~s}^{-1}\right)\end{array}$ & $\begin{array}{c}L_{\mathrm{p}} \\
(\mu \mathrm{m})\end{array}$ \\
\hline $\mathbf{1}$ & $7.2 \times 10^{16}$ & 62 & & & & \\
\hline $\mathbf{2}$ & $1.4 \times 10^{16}$ & 54 & $3 \times 10^{15}$ & $2 \times 10^{15}$ & 1.7 & 0.20 \\
\hline $\mathbf{3}$ & $8.9 \times 10^{15}$ & 54 & $9 \times 10^{15}$ & $3.5 \times 10^{15}$ & 0.3 & 0.37 \\
\hline
\end{tabular}


$0.1 \mathrm{eV}$ in the films of type 3 than in the films of type 2 [12]. Even more interesting, the diffusion length of holes $L_{\mathrm{p}}$, determined from surface photovoltage experiments, is higher in the films of type 3 than in the films of type 2 ( $\mathrm{Tab}$. III).

Figure 6 shows the density of states in the upper half of the gap determined from time-offlight and post-transit measurements for the samples of types 2 and 3 . We obtained these densities of states by assuming in both cases the same value of the microscopic mobility $\mu_{0}=10 \mathrm{~cm}^{2} \mathrm{~V}^{-1} \mathrm{~s}^{-1}$ and of the attempt-to-escape frequency $\nu_{0}=10^{12} \mathrm{~s}^{-1}$, two values widely used for «standard »a-Si : H. Contrary to what happens in the lower half of the gap, we here observe that i) the slope of the conduction band-tail (CBT) is the same $\left(T_{\mathrm{c}}=\right.$ $210 \mathrm{~K}$ ) for both types of films ; however the CBT appears to be shifted towards midgap for the film of type 3 ; ii) the density of states deeper in the gap is higher for the film of type $\mathbf{3}$ than for type 2. On the other hand, the electron drift mobility $\mu_{\mathrm{e}}$, measured at room temperature, is significantly lower (the relative error in the $\mu_{\mathrm{e}}$ measurements is of the order of $20 \%$ ) in the samples of type 3 than in the samples of type 2 (Tab. III).

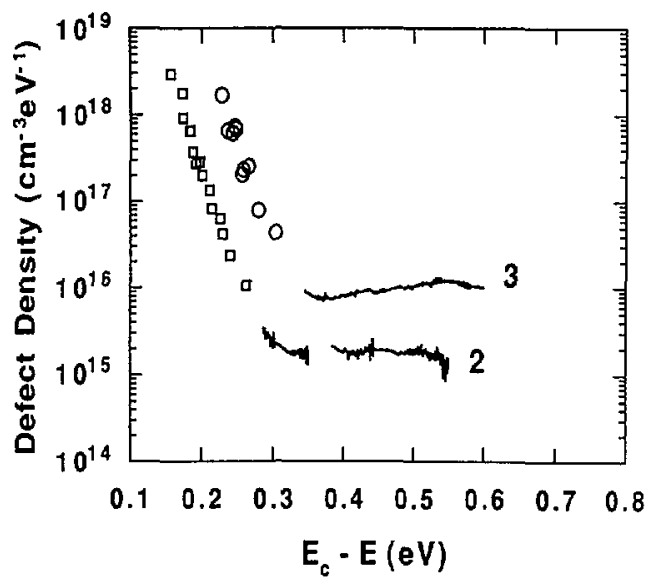

Fig. 6. - The density of states in the upper part of the gap determined by time of flight (symbols) and by post-transit measurements (continuous lines), for the films of types 2 and 3.

The position of the Fermi level $\left(E_{\mathrm{c}}-E_{\mathrm{F}}\right)$ was determined from the temperature dependence of the dark conductivity measured in a coplanar configuration. We find that $E_{\mathrm{F}}$ is about $0.15 \mathrm{eV}$ lower in the films of type 3 than in the films of type $2\left(E_{\mathrm{c}}-E_{\mathrm{F}}=0.75\right.$ and $0.9 \mathrm{eV}$ respectively). Moreover, the $(\mu t)_{\mathrm{e}}$ product was lower in the films of type 3 than in the films of type 2 by a factor of 10. This decrease of $(\mu t)_{\mathrm{e}}$ as well as the increase of $L_{\mathrm{p}}$ (Tab. III) is consistent with a general trend of the changes of the $(\mu t)_{\mathrm{e}}$ and $(\mu t)_{\mathrm{h}}$ products with $\left(E_{\mathrm{c}}-E_{\mathrm{F}}\right)[35,36]$. However, the shift of the Fermi level does not explain the decrease of the electron mobility determined from TOF experiments since these measurements are independent of the position of the Fermi level in undoped a-Si : $\mathbf{H}$ films.

In summary, for the «standard " and « helium-diluted » films deposited at $250{ }^{\circ} \mathrm{C}$ (types 2 and 3), the density of states and the VBT are the same in the lower half of the gap, whereas the density of states in the upper half of the gap is higher for the films of type 3. A reduction of the electron mobility and an enhancement of the hole diffusion length are observed in the films of type 3 as compared to the films of type 2. 


\section{Discussion.}

Let us first address the issue of hydrogen bonding and hydrogen evolution. The strong IR absorption band at $2070-2080 \mathrm{~cm}^{-1}$ observed in films 1 and 3 (Fig. 2) suggests that in both types of films hydrogen is bonded to silicon in a similar way. Now, the assignment of the band at $2090 \mathrm{~cm}^{-1}$ is still a subject of controversy. The former attribution of this band to polyhydride groups $\mathrm{Si}-\mathrm{H}_{2}$ and $\left(\mathrm{Si}-\mathrm{H}_{2}\right)_{n}$ [37] has been questioned on the basis of the lack of correspondence between the oscillator strengths of the $\sim 2100 \mathrm{~cm}^{-1}$ stretching band and the $\mathrm{Si}-\mathrm{H}_{2}$ bending bands in the $800-900 \mathrm{~cm}^{-1}$ range in films prepared under different conditions $[13,38]$. This would imply that, in some cases, some component of the stretching band at $\sim 2100 \mathrm{~cm}^{-1}$ has no bond bending counterpart, which suggests that it must be associated to monohydride groups ( $\mathrm{Si}-\mathrm{H})$. The shift of the $\mathrm{Si}-\mathrm{H}$ stretching mode from $2000 \mathrm{~cm}^{-1}$ to higher frequencies has been explained by environmental effects, the concerned $\mathrm{Si}-\mathrm{H}$ groups being located at internal surfaces or microvoids [38, 39, 40]. This interpretation has however also been questioned recently [41]. We have already emphasized in $\S 3.1$ that the relative strengths of the stretching band at $2070-2080 \mathrm{~cm}^{-1}$ and of the bending doublet at $840-880 \mathrm{~cm}^{-1}$ are the same for the films of type 1 and 3 , which, whatever the assignment of the $2070-2080 \mathrm{~cm}^{-1}$ band, confirms that the configurations of hydrogen bonding must be quite similar in both types of samples. On the other hand we do note that a shift of the Si-H stretching mode corresponding to monohydride groups, due to the presence of impurities (like oxygen) bonded to the same Si site $[42,43]$, can be discarded in all our samples which present a very low impurity level. Nevertheless, the striking difference between the hydrogen evolution spectra of the «standard $» \mathrm{a}-\mathrm{Si}: \mathrm{H}$ films deposited at $100{ }^{\circ} \mathrm{C}$ (Fig. 2) and of the « helium-diluted $»$ films deposited at $250^{\circ} \mathrm{C}$ (Fig. 4) clearly indicates that, though they have similar IR spectra, their microstructure is very different. This is also supported by the higher refractive index of the films of type 3 (Tab. II). We here emphasize the very particular behaviour of the hydrogen evolution for the films of type 3. Indeed, for a-Si : $\mathrm{H}$ samples deposited at similar deposition rates in discharges operated at higher frequency [44] the hydrogen evolution spectra shows a three peak profile in the 300 to $700{ }^{\circ} \mathrm{C}$ range, but no sharp peak at high temperature. The same kind of hydrogen evolution with three peaks, starting from $400^{\circ} \mathrm{C}$, is also observed in a-Si : $\mathrm{H}$ films deposited by reactive dc magnetron sputtering at lower deposition rates ( $\approx 2 \AA / s)$ [45] and for thick a-Si $: \mathrm{H}$ films deposited by RF glow discharge having columnar morphology [16].

One may suggest that the specific features of the hydrogen evolution for type 3 films are due to a thickness effect. Indeed, it is well known that for thick a-Si : $\mathrm{H}$ films, the high temperature TBH peak of the hydrogen evolution spectra shifts to a higher temperature [16]. However, we again point out that all the films studied here are thick and that we never observed such a narrow high temperature evolution peak for «standard" films whatever their substrate temperature and their thickness. We propose the following interpretation in order to explain the differences between the evolution spectra of type 1 and type 3 samples. In the « standard $»$ film deposited at $100^{\circ} \mathrm{C}$ the hydrogen evolution can be explained by the presence of interconnected voids (possibly related to a columnar microstructure), which provide a path for the evolution of hydrogen at low temperatures. On the contrary, in the « helium-diluted » film deposited at $250^{\circ} \mathrm{C}$ the hydrogen evolution suggests that there is no link between the microvoids. Thus, even if silicon-hydrogen bonds break at low temperature, hydrogen will not diffuse out but will rather be trapped in the microvoids and build up as molecular hydrogen. This in turn may explain the explosive behaviour at high temperature observed for films of type 3 as well as the fact that, during annealing, we often observe bubbles forming at the surface of these films.

Recent studies of the hydrogen dynamics in a-Si : $\mathrm{H}$ films prepared by $\mathrm{RF}$ sputtering have 
shown that the long-range motion of atomic hydrogen is suppressed when the microvoid content exceeds a critical value [46]. This is consistent with our results which show a large temperature delay for hydrogen evolution in the films of type 3 which have both a high hydrogen content and a high value of the parameter $R$, which must be related to the amount of microvoids. Thus, we consider that the hydrogen evolution observed for the films of type 3 has to be related to the particular growth conditions and the subsequent microstructure of these films. Studies are under way to better understand the role of the particular plasma conditions and the growth kinetics of these films and also to characterize the film microstructure. In any case, the results presented above clearly indicate that the so-called « microstructure parameter $\gg R$ deduced from the IR absorption spectra is not sufficient for a such characterization and is not a pertinent indication of the film « quality », at least when the deposition conditions are far from the «standard » ones.

The differences in the hydrogen-related microstructure influence the electronic properties of the films. Indeed we have already shown that the dark conductivity and the defect density of the films of type 3 do not show metastable effects induced by thermal quenching from $300{ }^{\circ} \mathrm{C}$ [12]. This contrasts with the electronic properties of the «standard » samples which depend on their thermal history (quenching or slow cooling) [47]. Such a dependence is well explained in the framework of thermal equilibrium models [48], where one considers that the silicon atoms form a rigid network, fixed by the deposition conditions, whereas bonded hydrogen can move through the silicon skeleton and thus modify the defect density. In this context a-Si : $\mathrm{H}$ is often considered as a hydrogen glass [49]. In the light of these models, the results of our hydrogen evolution experiments suggest that for the films of type 3 the motion of hydrogen is strongly reduced and, as a consequence, thermal treatments do not affect the defect density and thus the electronic properties of these films. Let us now consider the defect density closer.

As shown above (Fig. 5 and Tab. III), the type 3 films have a defect density in the lower half of the gap, as deduced from the low energy optical absorption, which is similar to that of type 2 films even though their hydrogen content and hydrogen bonding configurations suggest that they should rather behave like type 1 films. Consequently, in these films, there is no correlation between the density of states in the lower half of the gap and the hydrogen-related structure. On the contrary, if we turn to the density of states in the upper part of the gap, we observe that it is higher in type 3 than in type 2 films both in the band tail range and deeper in the gap. Indeed, even though the conduction band tail has the same slope, its shift towards mid-gap in type 3 films implies that, for a given energy, the density of states is higher in these films. Note however that from the TOF and post-transit measurements we deduced the product $\nu_{0} N(E) / \mu_{0}$, that we took the same values of $\mu_{0}$ and $\nu_{0}$ for all the films, and that the separation between $E$ and $E_{c}$, the energy of the conduction band mobility edge, is a function of $\nu_{0}$. Of course, this is a matter of discussion and we do not yet have enough arguments to decide among the different possibilities :

1) If indeed $\mu_{0}$ and $\nu_{0}$ are constant, which is our assumption for the results reported in figure 6 , the calculated density of states is correct and there is a parallel shift (by about $0.06 \mathrm{eV}$ ) of the conduction band tail towards mid-gap in type 3 samples with respect to type 2 samples. This seems to be in contradiction with the fact that for type 3 films the optical absorption edge shifts to higher energies, which is not the case for type 2 films. Moreover, under this assumption we obtain a deep defect state density which is five times higher in type 3 films than in type 2 films. Although the density of states at the Fermi level $g\left(E_{F}\right)$ and the integral of the density of states between midgap and the Fermi level $I_{\mathrm{mg}}$ show the same trends (see Tab. III) the differences between the values for type 3 and type 2 films are less important. This suggests that either $\mu_{0}$ or $\nu_{0}$ or both may change depending on the particular microstructure of the film. 
2) If $\mu_{0}$ and/or $\nu_{0}$ are not the same for films deposited under different conditions, the comparison reported in figure 6 is not correct. In any case, it is quite clear that any change in $\mu_{0}$ and/or $\nu_{0}$ has to be related to changes in the hydrogen incorporation, since the disorder of the silicon network remains the same (both the valence band tail and the conduction band tail keep the same slope). We then suggest that the existence of unconnected microvoids passivated by hydrogen in the films of type 3 may induce fluctuations of the conduction band edge which give rise to a shift of the effective onset of the conduction band tail deeper in the gap.

Potential fluctuations in a-Si $: \mathrm{H}$ and a-SiGe $: \mathrm{H}$ alloys have been largely discussed so as to explain the transport properties of these materials. Branz and Silver [50] proposed that potential fluctuations produced by inhomogeneities of the dielectric constant may cause the formation of charged dangling-bond defects in a-Si: $\mathrm{H}$. Howard and Street [51] also interpreted their results on the electron and hole drift mobilities in compensated a-Si : $\mathrm{H}$ as controlled by long-range potential fluctuations originating from charged donors and acceptors. It is also well established that the electron drift mobility of a-SiGe : $\mathrm{H}$ alloys decreases with the Ge content [29, 52], and again this decrease has been associated to long-range potential fluctuations in the alloys [53].

While we do not exclude the presence of charged defects in our samples giving rise to such long-range potential fluctuations, we propose an alternative explanation for the films of type 3 . We imagine them to resemble Swiss cheese in which the microvoids are saturated with hydrogen and have therefore a larger gap than the a-Si: $\mathrm{H}$ matrix around. The spatial gap fluctuations could then preferentially affect the conduction band edge, as observed for a-SiC : H/a-Si : $\mathrm{H}$ [54] and a-Si : H/a-SiGe : H [52, 55] interfaces. From the optical point of view the material would be composed of a matrix having the optical gap of a-Si : $\mathrm{H}$ and small regions (the microvoids saturated by hydrogen) with a higher optical gap. These differences would result in a mismatch of the conduction bands while the valence band of the two regions would be aligned, as in the case of the alloys. A strong argument in favor of this view is the fact that we do not observe any effect on the valence band tail, as should be the case for potential fluctuations originating from charged defects. In fact there is an improvement of the hole diffusion length.

Now, if one accepts the presence of potential fluctuations, whatever their origin, it is clear that they will reduce the electron mobility in extended states $\mu_{0}$, in which case the curve for the type 3 film in figure 6 should be corrected. Then the shift of the conduction band tail would tend to disappear and the defect density of states deeper in the gap would be smaller. This would be more consistent with the other data reported in table III. It is worthwhile noticing that the observed decrease of the electron drift mobility in type 3 films favours our interpretation.

The second possibility which could yield a different $N(E)$, namely an increase of $\nu_{0}$, has to be considered, too. Further experimental work is necessary to determine which one of the two parameters is dominant.

As a conclusion, the main result of the transport measurements is that the films of type 3 have a smaller electron drift mobility than the films of type 2 . At this point we do not have enough arguments to decide which mechanism can explain this difference. However, our results on the hydrogen-related properties lead us to the reduction of $\mu_{\mathrm{e}}$ as a consequence of long-range fluctuations of the conduction band edge promoted by the alloying effect of hydrogen. On the other hand, the surface photovoltage measurements indicate that the diffusion length of holes is increased in the films of type 3. Then, for this type of samples, we obtain a degradation of the transport of electrons along with an improvement of the transport of holes, which may be of great interest in applications like solar cells where the minority carriers control the performances of the device. From this point of view, the films of type 2 with a high 
$\mu_{\mathrm{e}}$ would be good candidates for Thin Film Transistor (TFT) devices and other applications where the electron transport is the crucial parameter, whereas the films of type 3 with a high $L_{\mathrm{p}}$ would be good candidates for solar cells and other applications where the hole transport is the limiting factor. Such modifications of $\mu_{\mathrm{e}}$ and $L_{\mathrm{p}}$ can be obtained by the addition of small amounts of dopants to the silane (in the ppm range), but it is well known that doping will introduce additional defects. On the contrary, the possibility of achieving a similar effect by just changing the plasma conditions, while keeping a low defect density, offers undeniable advantages.

To gain more insight into the correlation between the IR absorption spectra and the defect density, we annealed the films of type 1 at $200{ }^{\circ} \mathrm{C}$ for 2 hours. This temperature is of the order of the equilibration temperature determined for « standard samples [47]. A careful analysis of the IR spectra before and after annealing indicates that, within experimental uncertainties, no changes can be detected either in the hydrogen content or in the bonding configurations. However, the defect density is substantially changed after annealing, as demonstrated by the results reported in figures 6 and 7. In figure 7 we present the optical absorption spectra for the «standard » film deposited at $100^{\circ} \mathrm{C}$ (type 1) in both its as-deposited and annealed state. In agreement with previous publications $[56,57]$, we observe that the low energy absorption is much smaller after annealing, which indicates a strong reduction of the deep defect density. Then it is possible to have, for a given IR spectrum, a-Si : $\mathrm{H}$ films with very different defect densities. It could be argued that the IR absorption measurements are not sensitive enough to detect hydrogen-related changes at the concentration level of the defects. In any case, these results clearly show that, even for the samples deposited under « standard » plasma conditions, the correlation between the defect density and the presence of an absorption band at

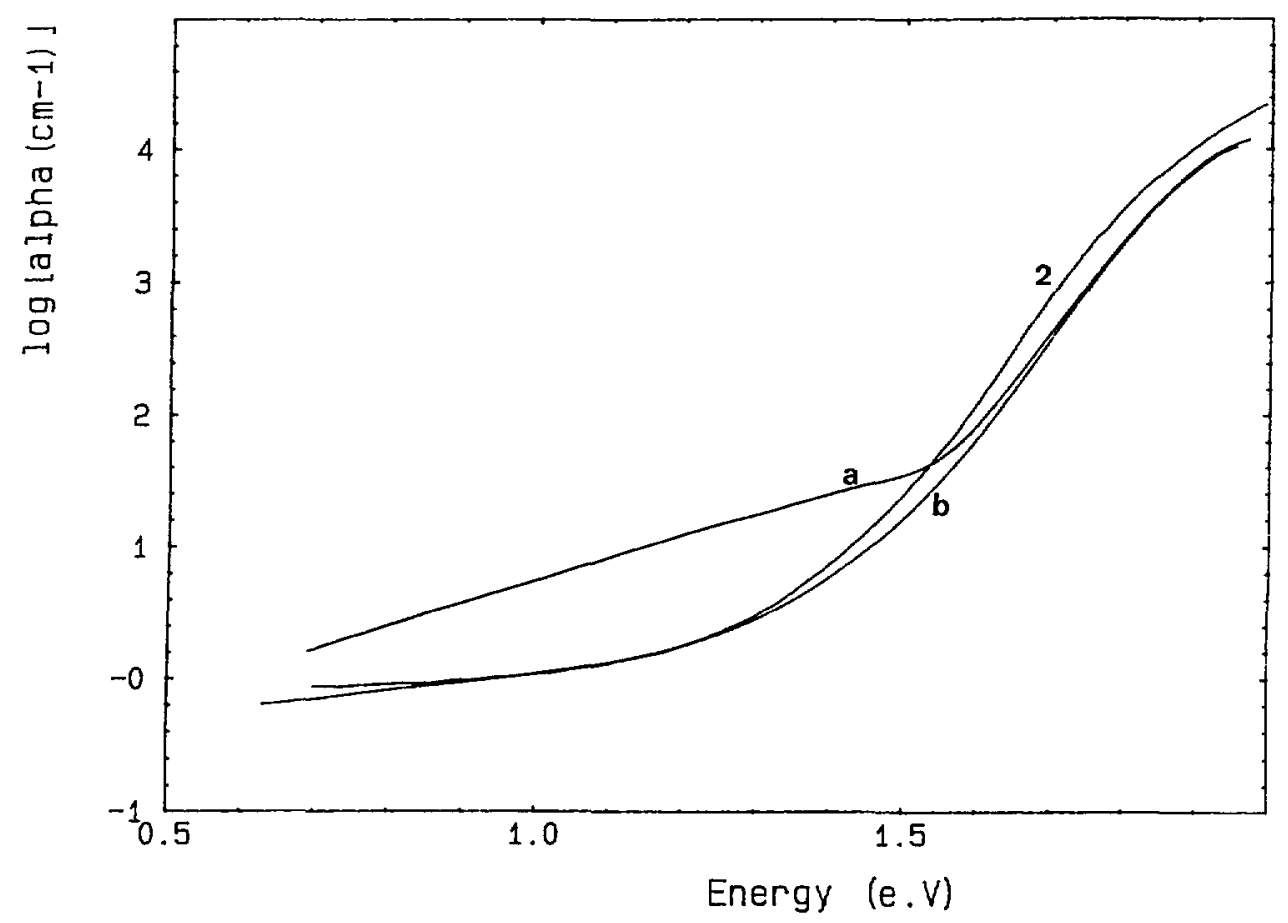

Fig. 7. - The optical absorption spectra of the films of type 1 (a) before and (b) after a 2-hour anneal at $200{ }^{\circ} \mathrm{C}$. The absorption spectrum of the films of type 2 is also included for comparison. 
$2080 \mathrm{~cm}^{-1}$ only applies to the material in its as-deposited state. The optical absorption spectrum of the «standard $»$ sample deposited at $250^{\circ} \mathrm{C}$ (type 2) is also reported in figure 7 for comparison. It is amazing to see that, although the annealed type 1 film has a larger optical gap (as expected from its higher hydrogen content) and a slightly larger Urbach energy, its lowenergy absorption coincides with that of the type $2 \mathrm{film}$. Therefore, the annealing of this film at $200{ }^{\circ} \mathrm{C}$ eliminated its native defects until the defect density characteristic of a film deposited under the same plasma conditions, but at higher temperature, was reached.

In figure 8 we present the density of states in the upper half of the gap, deduced from modulated photocurrent measurements. Like the PDS results, these results show that we can strongly reduce the defect density of the «standard $»$ film deposited at $100{ }^{\circ} \mathrm{C}$ (type 1) by annealing it at $200^{\circ} \mathrm{C}$. Moreover, its defect density after annealing is the same as that of the « helium-diluted » sample deposited at $250^{\circ} \mathrm{C}$ (type 3). However, contrary to the PDS results (Fig. 6), where the apparent decrease of the Urbach energy is due to the reduction of the deep defect contribution to the absorption and not to a reduction of the disorder (of the VBT width), annealing produces a sharpening of the conduction band tail, which could be attributed to a reduction of its potential fluctuations.

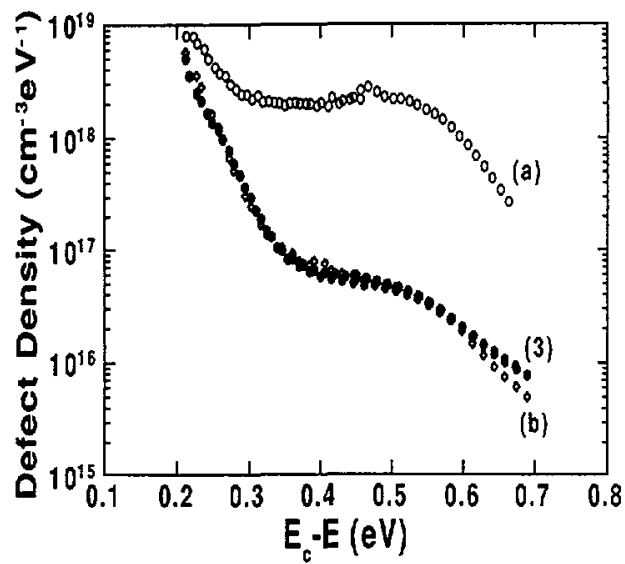

Fig. 8. - The defect density in the upper half of the gap of the films of type 1 (a) before and (b) after a 2hour anneal at $200^{\circ} \mathrm{C}$, compared to that of the films of type 3 in their as-deposited state.

\section{Conclusions.}

A comparative study of the hydrogen-related microstructure and of the optoelectronic properties of our «standard » a-Si : $\mathrm{H}$ films deposited by RF glow discharge from pure silane at two different temperatures and of a-Si : $\mathrm{H}$ films deposited by the same technique from a mixture of $40 \%$ silane in helium at higher deposition rates has shown that :

i) As already pointed out by many authors, there is a correlation between the defect density and the bonding of hydrogen in the «standard » a-Si: $\mathrm{H}$ films deposited from pure silane at low RF power, low pressure, and low deposition rates $(0.5-1 \AA / \mathrm{s})$. However this correlation is only valid for the films in their as-deposited state. Annealing the films deposited at low temperature at temperatures of the order of the equilibration temperature may substantially change this correlation. 
ii) This correlation does not apply to the films deposited at higher deposition rates (8$15 \AA / s)$ from a mixture of silane and helium under different plasma conditions. In particular, we have shown that despite a strong absorption band at $2080 \mathrm{~cm}^{-1}$, the films have a low defect density. Moreover, the optical measurements and the hydrogen evolution experiments indicate that these films are dense and that the evolution of hydrogen at low temperature is strongly reduced.

iii) We relate the particular hydrogen evolution of the films deposited from a mixture of silane in helium to the presence of microvoids with inner surfaces saturated by hydrogen. This hydrogen-related structure confers particular electronic properties to this material. Indeed we observe that whereas the density of states in the lower part of the gap is very close to that of the «standard » films, the density of states in the upper half of the gap increases and the electron drift mobility is reduced. The analysis of the transport measurements led us to assume that the conduction band edge is perturbed by potential fluctuations in the «helium-diluted» films. These fluctuations could originate from the mismatch of the conduction band between the a-Si : $\mathrm{H}$ matrix and the microvoids saturated by hydrogen and having a larger optical gap. The reduction of the electron drift mobility is accompanied by an increase of the diffusion length of the holes. Thus the deposition conditions can be adjusted to favor electron or hole transport, according to the desired application of the semiconductor.

In conclusion, the use of widely different deposition conditions for a-Si : $\mathrm{H}$ clearly reveals the advantages of the amorphous state, namely the possibility of tailoring the deposition conditions so as to obtain different a-Si: $\mathrm{H}$ materials with the adequate optoelectronic properties for each specific application.

\section{Acknowledgements.}

We thank J. Dixmier for stimulating discussions on the disorder and the microstructure of a-Si : $\mathrm{H}$ films ; D. Conne, M. J. Surmont and E. Caristan for their technical assistance. This work is supported by PIRSEM/CNRS and AFME.

\section{References}

[1] OGIer J., Bl. Soc. Chim. 8 (1979) 116.

[2] Chittick R. C., Alexander J. H. and Sterling H. F., J. Electrochem. Soc. 77 (1969) 116.

[3] Spear W. E. and Le Comber P. G., Solid State Commun. 17 (1975) 1193.

[4] See for example:

Solomon I., in Topics in Applied Physics, Vol. 36 : Amorphous Semiconductors, M. H. Brodsky Ed. (Springer-Verlag, 1979);

LEY L., in Topics in Applied Physics, Vol. 56: The Physics of Hydrogenated Amorphous Silicon II, J. D. Joannopoulos and G. Lucovsky Eds. (Springer-Verlag, 1984).

[5] See for example Amorphous and Microcrystalline Semiconductor Devices, J. Kanicki Ed. (Artech House, Boston-London, 1991).

[6] Roca i Cabarrocas P., Chévrier J. B., Huc J., Lloret A., Parey J. Y. and Schmitt J. P. M., J. Vac. Sci. Technol. A 9 (1991) 2331.

[7] Knights J. C. and Lujan R. A., Appl. Phys. Lett. 35 (1979) 244.

[8] Lucovsky G., Dayidson B. N., Parsons G. N. and Wang C., J. Non Cryst. Solids 114 (1989) 154.

[9] Perrin J., Roca i Cabarrocas P., Allain B. and Friedt J. M., Jpn J. Appl. Phys. 27 (1988) 2041. 
[10] Roca i Cabarrocas P., Vanderhaghen R., Bouizem Y., Thèye M. L., Mencaraglia D., Diebbour Z., Sib J., Kleider J. P., Longeaud C. and Glodt O., Proc. of the 10th ECPVSEC, A. Luque, G. Sala, W. Palz, G. Dos Santos and P. Helm Eds. (Kluwer Academic Publishers, 1991) p. 1083.

[11] Roca i Cabarrocas P., Bouizem Y. and Thèye M. L., Philos. Mag. (to be published).

[12] Meaudre R., Meaudre M., Roca I Cabarrocas P., Tanidi S., Bouizem Y. and ThèYe M. L., $J$. Non Cryst. Solids $137 \& 138$ (1991) 171.

[13] Shanks H., Fang C. J., Ley L., Cardona M., Demond F. J. and Kalbitzer S., Phys. Stat. Sol. (b) 100 (1980) 43.

[14] Fang C. J., Gruntz K. J., Ley L., Cardona M., Demond F. J., Muller G. and Kalbitzer S., $J$. Non Cryst. Solids 35 \& 36 (1980) 255.

[15] Bhattacharya E. and Mahan A. H., Appl. Phys. Lett. 52 (1988) 1587.

[16] Biegelsen D. K., Street R. A., Tsai C. C. and Knighrs J. C., Phys. Rev. B 20 (1979) 4839.

[17] Beyer W. and Wagner H., J. Non Cryst. Solids 59 \& 60 (1983) 161.

[18] Sardin G., Andreu J., Delgado J. C. and Morenza J. L., Solar Energy Mater. 17 (1988) 227.

[19] L'Ecuyer J., Brassard C., Cardinal C., Chabbal J., Dechenes L., Labrie J. P., Terrault B., Martel J. G. and St. JacQues R., J. Appl. Phys. 47 (1976) 881.

[20] Wemple H. and Didomenico M., Phys. Rev. 3 (1971) 1338.

[21] Amer N. M. and Jackson W. B., Semiconductors and Semimetals, J. I. Pankove Eds., Vol. 21B (1984) p. 83.

[22] Kleider J. P., Longeaud C. and Glodt O., J. Non Cryst. Solids 137 \& 138 (1991) 447.

[23] Kleider J. P.. Mencaraglia D. and Djebbour Z., J. Non Cryst. Solids 114 (1989) 432.

[24] Longeaud C. and Vanderhaghen R., Philos. Mag. B 61 (1990) 277.

[25] Seynhaeve G. F., Barclay R. P., Adriaenssens G. J. and Marshall J. M., Phys. Rev. B 39 (1989) 10196.

[26] Moore A. R., in Semiconductors and Semimetals, Vol. 21 Part C, J. 1. Pankove Ed. (Academic Press, Inc., 1984) p. 239.

[27] Ritter D., Weiser K. and Zeldov E., J. Appl. Phys. 62 (1987) 4563.

[28] Balberg I. and Weisz S. Z., Appl. Phys. Lett. 59 (1991) 1726.

[29] Mencaraglia D., Kleider J. P., Longeaud C., Duebbour Z., Hadrami M., Godet C. and Vanderhaghen R., Proc. of the 9th ECPVSEC, W. Palz, G. T. Wrixon and P. Helm Eds. (Kluwer Academic Publishers, 1989) p. 91.

[30] Chabal J. Y. and Patel C. K. N., Rev. Mod. Phys. 59 (1987) 835.

[31] Boyce J. B. and Stutzman M., Phys. Rev. Lett. 54 (1985) 562.

[32] Knights J. C., Lucovsky G. and Nemanich R. J., J. Non Cryst. Solids 32 (1979) 393.

[33] van den Heuvel J. C., Geerts M. J. and Metselaar J. W., Solar Energy Mater. 22 (1991) 185.

[34] Roca I Cabarrocas P., Thèse de l'Université de Paris VII (1988) in French.

[35] Kocka J., Nebel C. E. and Abel C. D., Philos. Mag. B 63 (1991) 221.

[36] PaI D. M. and Abkowitz M., J. Non Cryst. Solids 115 (1989) 213.

[37] Brodsky M. H., Cardona M. and Cuomo J. J., Phys. Rev. B 16 (1977) 3556.

[38] PaUl. W., Solid State Commun. 34 (1980) 283.

[39] Cardona M., Phys. Stat. Sol. (b) 118 (1983) 463.

[40] WAGNer H. and BEYER W., Solid State Commun. 48 (1983) 586.

[41] CHEN Y. F., Solid State Commun. 71 (1989) 1127.

[42] Knights J. C., Street R. A. and Lucovsky G., J. Non Cryst. Solids 35 \& 36 (1980) 279.

[43] Lucovsky G., Solid State Commun. 20 (1979) 571.

[44] Finger F., Viret V., Shah A., Tang X.-M., Weber J. and Beyer W., in Amorphous Silicon Technology, P. C. Taylor, M. J. Thompson, P. G. Le Comber, Y. Hamakawa and A. Madan Eds., MRS Symp. Proc. 192 (1990) 583-588.

[45] Maley N., Myers A., Pinabarasi M., Leet D., Abelson J. R. and Thornton J. A., J. Vac. Sci. Technol. A 7 (1989) 1267.

[46] Shinar J., Shinar R., Mitra S. and Kim J.-Y., Phys. Rev. Lett. 62 (1989) 2001.

[47] Meaudre R., Jensen P. and Meaudre M., Philos. Mag. B 63 (1991) 815.

[48] Street R. A., Kakalios J., Tsai C. C. and Hayes T. M., Phys. Rev. B 35 (1987) 1316. 
[49] Kakalios J. and Jackson W. B., Amorphous Silicon and Related Materials, Hellmut Fritzche Ed. (World Scientific Publishing Company, 1988) pp. 207-245.

[50] Branz H. M. and Silver M., Phys. Rev. B 42 (1990) 7420.

[51] Howard J. A. and Street R. A., Phys, Rev. B 44 (1991) 7935.

[52] Aluishi S., Smith Z. E., Slobodin D., Kolodzey J., Chu V., Schwartz R. and Wagner S., Mat. Res. Symp. Proc. D. Adler Ed., 70 (Materials Research Society, Pittsburg, 1986) p. 81.

[53] von RoEdern B. and Madan A., Philos. Mag. B 63 (1991) 293.

[54] Wu Z. Y., SIEFERT J. M. and EQueR B., Proc. 10th European Photovoltaic Solar Energy Conference, A. Luque, G. Sala, W. Palz, G. Dos Santos and P. Helm Eds. (Kluwer Academic Publishers, Dordrecht, 1991) p. 953.

[55] Evangelisti F., J. Non Cryst. Solids 77 \& 78 (1985) 969.

[56] Parsons G. N., Wang C., Williams M. J. and Lucovsky G., J. Non Cryst. Solids 114 (1989) 178.

[57] Kunst M. and Neitzert H.-C., J. Appl, Phys. 69 (1991) 8320. 


\section{Revue de livres}

$\underline{\text { Statistics }}$

R. J. BARLOW

(Wiley, 1990), 204 p., £ 9.95, ISBN 0-471-92295-1.

Comme son sous-titre l'indique : a guide to the use of statistical methods in the physical sciences, ce livre, placé dans la série Manchester Physics Series et dérivant directement de notes de cours, est destiné à l'initiation des étudiants en physique. Il comporte dix chapitres traitant du bon usage de la statistique, des quantités utilisées pour décrire les données, des distributions statistiques, des erreurs, du problème de l'estimation, des méthodes de moindres carrés, etc. L'ensemble est plutôt facile à lire, les exemples sont nombreux et les sujets plus difficiles ou moins importants en première lecture sont signalés par des étoiles. Les conseils nombreux et lucides seront appréciés des étudiants. Au total, un livre pratique, ne s'embarrassant pas de considérations théoriques trop poussées, à recommander à son public potentiel de physiciens débutants.

Paul Manneville (Saclay).

\section{Fusion. The Search for Endless Energy}

Robin HERMAN

(Cambridge University Press, 1990, reprint 1991), 261 p. + index, £ 13.95, \$19.95, ISBN 0521-38373-0 hardback.

When scientists become too arrogant about their power to change the world they should look at the cautionary example of controlled nuclear fusion. The ingredients have been there for decades : the knowledge that $E=m c^{2}$, abundant deuterium for fuel, astrophysical examples shining from the sky and uncontrolled fusion bombs to prove that it can be done on earth. But building a fusion reactor has turned out to be a great deal more difficult than pioneers like Lyman Spitzer of Princeton University expected when the first test reactors were designed in 1951.

Can «the first female sports reporter on The New York Times », now « a science and health writer... ", present such a technical and difficult story? This book proves that she scan. There is no attempt to explain the complexities of plasma physics in depth, but they are reported in the words of the leading fusion scientists in a way which makes them sufficiently understandable for the lay reader to grasp their importance. The one-paragraph personality-pieces on scientists are reminiscent of the sports pages. For instance, describing the setting up of the team to build the Joint European Torus (JET), « Paul Henri Rebut of France was chosen as the design team director. "The mad Rebut ", as he would come to be called, was summoned from Fontenay-aux-Roses, the fusion lab outside of Paris... He was enamoured of building practical things. To move to his new job, Rebut set sail across the English Channel (like William the Conqueror it is said) on a sloop of his own design... » But sporting analogies and short character sketches are perfectly appropriate for the account of the "Plasma Olympics » of the cold war period, the biennial international Atoms for Peace conferences at which the West and the Soviets vied with one another to impress the world and upstage the other side.

She gives full credit to the Russian teams who developed the "tokamak» idea and pressed their political masters to reveal it to the West. As told here, the Russian initiative jumped the rest of the world out of a theoretical phase of trying to understand the why plasmas are unstable into the more experimental approach of making them less unstable. This approach has worked, and the story is told quite dramatically of how the latest generation of big tokamaks. TFTR in Princeton and Jet in Europe have vied with each other to approach the immediate goal ; "ignition », where the fusion reaction, once started, will sustain itself for seconds without further input of energy. The lesson from these experiments is a 
simple but sobering one; if the machines can be built big enough then fusion will ultimately be controllable. The problem is the cost.

There are entertaining descriptions of the strange and erratic supporters who have rallied to the cause of fusion over the years, from President Juan Peron of Argentina - whose misguided announcement of a successful fusion reactor in 1951 first started Lyman Spitzer thinking about how to do it properly through to Bob Guccione of Penthouse magazine who was persuaded to put $\$ 16$ million into a novel tokamak in the early 1980s. The main stream of fusion research is concerned with magnetic confinement of the hot plasma but the alternatives get a mention; the short-lived Easter sensation of 1989 when Fleischman and Pons reported «cold fusion» inside the paladium electrodes of a heavy-water cell, as well as serious alternatives like laser confinement and ion-beam inertial confinement.

This is a journalist's book, but the detail and the storytelling turn it into a very readable popular history of an important subject. It is accessible to the educated lay reader and will be useful to the scientist who wants to know something about when things happened and how the decisions were made.

David J. MiLLeR (University College, London).

\section{Nonlinear Dynamics and Neural Networks}

H. G. SCHUSTER, Ed.

(Série : Nonlinear Systems : Concepts, Methods, Applications, Vol. 2 (VCH, 1991)), 338 p., 164.00 DM, ISBN 3-527-28342-0.

Using the phenomenon of collective neuronal oscillation as a focal point, « Nonlinear Dynamics and Neuronal Networks », treats a wide range of issues in the biology, physics, psychology and philosophy of the brain. This book is a collection of articles edited by H. G. Schuster and published by VCH in 1991 . It contains contributions from a good number of the leading workers in the field. Any neural-network professional will recognize many of the authors, and will likely have heard some of the arguments before, but perhaps never in so well-organized a format nor synthetic a context.

The overall project is ambitious and is structured bottom up. It begins with reviews on laboratory measurements of temporally coherent neuronal behavior, and ends with considerations of high-level representations of space and time. Still, the major emphasis is on methodological issues in the middle ground : what can and should be measured in the laboratory? Which mathematical tools can and should be used to treat these measurements? Further, these issues are raised largely with reference to a particular biological system, visual cortex, and a to a particular philosophical psychology problem, the binding problem.

The problematic is set out in the first article which reviews the physiological evidence for oscillations in striate and extra-striate cortex and some ideas for how these observations pertain to the problem of «binding 》 different features, possibly even from different sensory modalities, together with each other and to the object which "possesses » these features. The basic intuition is that feature coherence is mediated by temporal coherence. From this first article the book proceeds in a cleverly edited fashion to emphasis first more the experimental aspect, then more the modeling aspect, then more the integration of theory and experiment.

Along the way a second major theme emerges. The temporal coherence under discussion takes place in a network with a high degree of spatial structure. How are temporal and spatial structure related ? In particular, how is coherency of activity in a set of cells spatially organized say as a local group or layer meaningfully connected up with coherency in other groups or layers?

It is inevitable that spatio-temporal organization in brain activity will move toward the center of concern of neuroscience in the coming years. This book will be of interest to all seeking to understand the current state of the art. The authors have made efforts to address non-specialists and specialists alike. producing research reports containing reasonably in-depth reviews, so that the volume serves well as a graduate textbook.

H. Gutowirz (ESPCI). 


\section{Cellular Automata, Theory and Experiments}

H. GuTowitz, Ed.

(MIT Press, 1991), 490 p., \$50.50, ISBN 0-262-57086-6.

Les automates cellulaires sont des systèmes dynamiques très simples généralement définis sur un réseau régulier, disposant d'un nombre fini d'états par sites et évoluant selon une règle de mise à jour synchrone (temps discret). Malgré cette définition simple, ils sont capables d'une évolution globale complexe, possèdent des propriétés d'auto-organisation, permettent même dans certains cas d'effectuer des calculs élémentaires. A ces multiples titres ils ont fait l'objet de nombreux travaux que ce soit dans le domaine des mathématiques appliquées, du traitement de l'information, de la modélisation des processus complexes en physique, chimie, biologie. De nombreuses conférences leur ont été consacrées. Le livre édité par Howard Gutowitz, actuellement à l'Ecole de Physique et Chimie, contient les contributions présentées à l'une de ces conférences, tenue en septembre 1989 à Los Alamos, haut lieu de la dynamique non linéaire. C'est en fait une réédition par MIT Press d'un volume initialement paru à Physica D (vol. 45, 1990). Malgré le délai qui sépare la tenue de la conférence de la publication de ce livre, l'initiative de la réédition reste excellente car il contient de nombreux articles très intéressants, à commencer par la longue introduction de l'éditeur lui-même qui situe bien les problèmes. Six chapitres composent le volume, allant de l'analyse mathématique aux applications. Le problème direct concerne plutôt la déduction des propriétés à partir de la connaissance de la règle. Le problème inverse, celui de déterminer la règle connaissant les propriétés, intéresse lui plus directement les applications (construction de modèles explicites e.g. de morphogenèse). Ces deux aspects sont l'objet de nombreuses contributions (34 au total). Les deux premiers chapitres sont dédiés aux propriétés mathématiques et à la structure de l'espace des règles puis, plus loin, le chapitre 5 à la théorie du calcul. La détermination de règles présentant des caractères particuliers fait l'objet du chapitre 3 et les applications à la biologie et à la physique celui du chapitre 4 . Quelques généralisations sont considérées au chapitre 6 . Un premier appendice présente les ensembles logiciels et matériels destinés à la simulation d'automates et un second, dû à l'éditeur, donne une carte permettant de s'orienter dans l'abondante littérature récente sur les automates cellulaires.

Au total, nous sommes en présence d'un volume utile même si l'abord de certaines contributions est difficile en raison de leur extrême technicité.

P. Manneville (Saclay). 